\title{
HUBUNGAN FAMILY CENTERED CARE DENGAN DAMPAK HOSPITALISASI PADA ANAK PRASEKOLAH DI RUANG BAJI MINASA RSUD LABUANG BAJI MAKASSAR
}

\author{
Sunarti \\ Prodi Keperawatan Fakultas Kesehatan Masyarakat \\ Universitas Muslim Indonesia
}

\begin{abstract}
ABSTRAK
Proses hospitalisasi merupakan proses perawatan yang dijalani anak selama berada di rumah sakit. Hospitalisasi anak usia 3-6 tahun merupakan kondisi yang tidak menyenangkan karena anak mengalami hal-hal yang menimbulkan steres seperti kehilangan kendali, cedera fisik dan lingkungan yang asing. Sebab itu, dibutuhkan lingkungan yang mendukung agar mengurangi dampak hospitalisasi pada anak. Keterlibatan orang tua dalam mengambil keputusan dan kerjasama yang baik dengan perawat merupakan bentuk asuhan keperawatan dengan pendekatan Family Centered Care. Tujuan penelitian ini adalah untuk mengetahui hubungan Family Centered Care dengan dampak hospitalisasi pada anak prasekolah di ruang Baji Minasa. Metode penelitian ini menggunakan survey analitik dengan pendekatan cross sectional, jumlah sampel sebanyak 53 responden. Hasil penelitian didapatkan ada hubungan yang signifikan penyampaian informasi dengan dampak hospitalisasi pada anak prasekolah dengan nilai $\rho=0,00$, ada hubungan partisipasi keluarga dengan dampak hospitalisasi pada anak prasekolah dengan nilai $\rho=0,03$, dan ada hubungan kerja sama keluarga dengan dampak hospitalisasi pada anak prasekolah dengan nilai $\rho=0,001$. Kesimpulan penelitian ini adalah ada hubungan signifikan antara Family Centered Care (penyampaian informasi, partisipasi keluarga, dan kerjasama keluarga) dengan dampak hospitalisasi pada anak prasekolah di RSUD Labuang Baji Makassar. Untuk itu diharapkan perawat perlu untuk mempertahankan penerapan Family Centered Care untuk meningkatkan pelayanan melalui asuhan keperawatan.
\end{abstract}

Kata kunci : Family Centered Care, hospitalisasi

\section{ABSTRACT}

Hospital is a process of care that a child goes through while in hospital. Hospitalization of children aged 3-6 years is an unpleasant condition because children experience things that cause stress such as loss of control, physical injury and an unfamiliar environment. Therefore, a supportive environment is needed to reduce the impact of hospitalization on children. The involvement of parents in making decisions and good cooperation with nurses is a form of nursing care with the Family Centered Care approach. The purpose of this study was to determine the relationship of Family Centered Care with the impact of hospitalization on preschool children in the Minasa Baji room. This research method uses analytic survey with cross sectional approach, with a total sample of 53 respondents. The results showed that there was a significant relationship between the delivery of information and the impact of hospitalization on preschool children with a value of $\rho=0.00$, there is a relationship of family participation with the impact of hospitalization on preschool children with a value of $\rho=0.03$ and there is a relationship of family cooperation with the impact of hospitalization on preschool children with a value of $\rho=0.001$. The conclusion of this study is that there is a significant relationship between Family Centered Care (delivery of information, family participation, and family collaboration) with the impact of hospitalization on preschool children in Labuang Baji Hospital Makassar. For this reason it is hoped that nurses need to maintain the application of Family Centered Care to improve services through nursing care. 
Alamat korespondensi: Jl.Urip Sumoharjo KM.5 Program Studi Ilmu Keperawatan Universitas Muslim Indonesia, Makassar, Sulawesi Selatan

Email: sunarti83ners@gmail.com

\section{PENDAHULUAN}

Proses pertumbuhan dan perkembangan yang dilalui oleh manusia bersifat individual yang dipengaruhi oleh kesehatan individu secara holistik. Sebagai suatu proses, pertumbuhan dan perkembangan berlangsung secara bertahap, artinya pertumbuhan dan perkembangan pada suatu tahap mempengaruhi tahap selanjutnya. Oleh karena itu, untuk mencapai keberhasilan dalam setiap tahap pertumbuhan dan perkembangan perlu adanya pemahaman tentang tumbuh dan kembang sejak awal yaitu pada masa kanak-kanak. Pertumbuhan dan perkembangan yang optimal pada usia pra sekolah, dipengaruhi oleh status kesehatan yang baik. Status kesehatan yang baik digambarkan dengan keadaan yang sehat dan bebas dari penyakit. Status kesehatan yang buruk, dapat menghambat pertumbuhan dan perkembangan anak dan berpengaruh hingga anak itu dewasa. Dalam kondisi sakit, terkadang anak diharuskan untuk menjalani perawatan di rumah sakit. Proses ini disebut dengan hospitalisasi, (Potter \& Perry, 2005).

Pada proses hospitalisasi, anak cenderung mengalami kecemasan karena takut terhadap lingkungan rumah sakit, prosedur tindakan atau bahkan kematian, perpisahan, keterbatasan privasi dan melakukan kegiatan rutinitas, (Wong, 2009). Pengalaman hospitalisasi dapat mengganggu psikologi seseorang terlebih bila seseorang tersebut tidak dapat beradaptasi dengan lingkungan barunya di rumah sakit (Edi Novriadi, 2012 dikutip dari Hudriyah, 2013).

Menurut Centers for Disease Control and Prevention (CDC) berdasarkan survey dari WHO pada tahun 2012 hingga 2013, Tingkat rawat inap untuk anak-anak 0-4 tahun adalah 57,2 per 100.000 penduduk, sedangkan di Indonesia sendiri berdasarkan survey kesehatan ibu dan anak tahun 2012 didapatkan bahwa dari 1.425 anak mengalami dampak hospitalisasi, dan 33,2\% diantaranya mengalami dampak hospitalisasi berat, 41,6\% mengalami dampak hospitalisasi sedang, dan 25,2\% mengalami dampak hospitalisasi ringan. Di Indonesia jumlah anak usia prasekolah (3-5 tahun) berdasarkan Badan Pusat Statistik tahun 2014 sebesar 4\% dari jumlah total penduduk Indonesia. Berdasarkan data tersebut, dapat diperkirakan 25 per 100 anak mengalami hospitalisasi. (CDC, 2015)

Rasa cemas, nyeri ataupun ketidak nyamanan lainnya yang dialami anak saat berada di rumah sakit merupakan reaksi yang membutuhkan pendampingan dari orang tua, sehingga memberi rasa nyaman pada anak dalam menjalani proses hospitalisasi, terutama ketika anak mendapat terapi pemberian cairan intravena dan injeksi obat-obatan lainnya. (Wong, 2009). Sesuai dengan filosofi keperawatan anak yaitu Family Centered Care, yang melibatkan peran keluarga dalam perawatan anak sakit. Dengan demikian memberi arti Pentingnya keterlibatan keluarga dalam memberikan perawatan pada anak di rumah sakit, (Hidayat, 2005)

Dalam praktik keperawatan anak, asuhan keperawatan yang diterapkan berdasarkan pada filosofi keperawatan anak. Filosofi keperawatan anak merupakan keyakinan atau pandangan yang dimiliki oleh perawat untuk memberikan pelayanan kepada anak. (Hidayat, 2005).

Dalam sebuah penelitian yang dilakukan di RSUP. Dr. Wahidin Sudirohusodo Makassar oleh Hudriah (2013), menjelaskan bahwa dari 14 responden ada 8 responden yang menyatakan mendapat dukungan keluarga dan tidak ada dampak hospitalisasi, sedangkan 6 responden menyatakan kurang mendapatkan dukungan keluarga dan mengalami dampak hospitalisasi. Sedangkan untuk lingkungan rumah sakit, dari 14 responden ada 7 responden menyatakan lingkungan baik tetapi ada reaksi hospitalisasi dan 7 responden menyatakan lingkungan kurang baik dan ada reaksi hospoitalisasi. Berdasarkan hasil penelitian tersebut disimpulkan bahwa ada 
hubungan antara dukungan keluarga dengan reaksi hospitalisasi pada anak usia sekolah dan ada hubungan antara lingkungan rumah sakit dengan reaksi hospitalisasi pada anak sekolah di RSUP Dr. Wahidin Sudirohusodo Makassar, (Hudriyah, 2013).

Penelitian yang terkait lainnya adalah penelitian yang dilakukan di Panti Wilasa Citarum Semarang oleh Fiane (2012), menjelaskan bahwa gambaran efek hospitalisasi pada anak usia 3-6 tahun menurut 14 orang tua berada dalam kategori sedang, sedangkan 20 orangtua menyatakan efek hospitalisasi padak anak dinilai rendah. Sedangkan penerapan Family Centered Care oleh perawatan yang dinilai oleh orang tua sebanyak 31 orang atau 98,18\% menyatakan bahwa pelaksanaan Family Centered Care dinilai baik, sedangkan 3 orang atau 8,82\% menyatakan bahwa pelaksanaan Family Centered Care dinilai cukup. Berdasarkan hasil penelitian tersebut maka disimpulkan bahwa ada hubungan antara family centered care dengan efek hospitalisasi pada anak prasekolah di Panti Wilasa Citarum Semarang. (Fiane, 2012.)

Berdasarkan studi kasus pendahuluan pada tanggal 20 April 2015 di RSUD Labuang Baji Makassar melalui observasi dan wawancara dengan 5 orang tua didapatkan hasil bahwa untuk dukungan keluarga terdapat 2 orang tua yang tidak ikut serta dalam proses perawatan anak, yaitu dalam melakukan tindakan sebagian perawat tidak memberikan penjelasan tentang tindakan keperawatan seperti pemberian obat dan memberikan informasi tentang kondisi anaknya yang dirawat. Dari 6 orang tua, terdapat 4 orang tua mengatakan bahwa anaknya menangis ketika disuntik, dipasang infus dan diambil darah untuk pemeriksaan laboratorium.

Rumah Sakit Umum Daerah Labuang Baji merupakan rumah sakit tipe B yang terletak di Kota Makassar. Di RSUD Labuang Baji Makassar pada tahun 2014 terdapat 1465 anak dan diantaranya sebanyak 344 anak usia prasekolah yang dirawat di RSUD tersebut., sedangkan pada bulan Januari sampai April 2015 terdapat 568 anak dan diantaranya sebanyak 119 anak usia prasekolah. Salah satu tenaga kesehatan yang bertugas di RSUD Labuang Baji Makassar adalah perawat. Perawat anak memiliki tugas dan peran yaitu sebagai pemberi pelayanan keperawatan pada anak yang terjadi mulai dari masalah yang yang bersifat sederhana sampai yang kompleks seperti memberi makan, dan memandikan, serta perawat juga bertanggung jawab dalam hal pendidikan dalam bentuk penyuluhan kesehatan tentang masalah kesehatan yang dialami anak, termaksud memfasilitasi keluarga dalam perawatan anaknya.

\section{TUJUAN}

Tujuan dalam penelitian ini adalah untuk mengetahui hubungan Family Centered Care (penyampaian informasi kepada keluarga, partisipasi orang tua dalam pengambilan keputusan dan kerjasama antara orang tua dan perawat) dengan dampak hospitalisasi pada anak prasekolah di ruang Baji Minasa RSUD Labuang Baji Makassar.

\section{METODE PENELITIAN}

Penelitian ini merupakan penelitian survey analitik dengan pendekatan cross sectional study. Penelitian ini dilakukan di ruang perawatan Baji' Minasa RSUD Labuang Baji Makassar pada tanggal 1 Juni sampai dengan 7 Juli 2015. Populasi pada penelitian ini adalah seluruh pasien anak usia prasekolah (usia 3 sampai 6 tahun) yang menjalani hospitalisasi yaitu sebanyak rata-rata 119 anak setiap bulannya di RSUD Labuang Baji Makassar selama bulan Januari hingga April 2015.

Penentuan sampel dilakukan dengan menggunakan purposive sampling. Jumlah sampel sebanyak 119 anak yang memenuhi kriteria inklusi dan eksklusi yaitu; Keluarga yang memiliki anak usia prasekolah (usia 3 sampai 6 tahun) yang menjalani proses hospitalisasi di RSUD Labuang Baji Makassar minimal selama 1×24 jam; Anak prasekolah yang pernah melakukan pemasangan infus berulang, Keluarga baik orang tua ataupun saudara dalam keadaan sehat jasmani dan mental; Keluarga baik orang tua ataupun saudara yang dapat berkomunikasi secara verbal atau lisan, Keluarga baik orang tua ataupun saudara yang dapat membaca dan menulis dan Bersedia menjadi responden. Adapun kriteria ekslusi dalam penelitian ini terdiri dari keluarga 
dengan anak yang mengalami syndrome down, retardasi mental atau hiperaktif dan keluarga dengan anak yang mengalami penyakit kronik.

Adapun Instrumen yang digunakan dalam penelitian ini berupa kuesioner yang terdiri atas 2 bagian, yaitu Kuesioner Family Centered Care yang terdiri dari 25 pertanyaan tertutup dengan pembagian sup pokok pertanyaa yaitu penyampaian informasi kepada keluarga sebanyak 10 pertanyaan, Kuesioner partisipasi orangtua dalam pembuatan keputusan sebanyak 4 pertanyaan, Kuesioner kerjasama dengan orang tua dan perawat sebanyak 11 pertanyaan. Pertanyaan disusun menggunakan skala Gutman (ya : 1; tidak : 0). Jawaban ya jika sesuai dengan keadaan responden dan tidak jika tidak sesuai dengan keadaan responden. Kuesioner dampak hospitalisasi anak yang terdiri dari 12 pertanyaan tertutup. Pertanyaan disusun menggunakan skala Gutman （ya : 1; tidak : 0). Jawaban ya jika sesuai dengan keadaan responden dan tidak jika tidak sesuai dengan keadaan responden. Penelitian ini menggunakan analisis univariat dan bivariat dengan Uji statistik chi square, dengan taraf signifikan $a=0,005$ atau tingkat kepercayaan $95 \%$.

\section{Hasil}

Karakteristik Responden

Karakteristik responden menggambarkan karakteristik keluarga dan karakteristik anak. Karakteristik keluarga terdiri dari umur, status hubungan dengan pasien, pendidikam keluarga, status pernikahan, dan penghasilan. Karakteristik anak terdiri dari jenis kelamin, umur pasien dan lama perawatan.

Tabel 1. Karakteristik Responden Berdasarkan Umur, status Hubungan dengan Pasien, pendidikan keluarga dan status pernikahan Keluarga yang Memiliki Anak Prasekolah Di Ruang Baji Minasa RSUD Labuang Baji Makassar

\begin{tabular}{ccc}
\hline Umur & \multicolumn{3}{c}{ Jumlah } \\
\cline { 2 - 3 } & $\mathrm{n}$ & $\%$ \\
\hline $20-29$ tahun & 22 & 41,5 \\
$30-39$ tahun & 25 & 47,2 \\
$\geq 40$ tahun & 6 & 11,3 \\
Total & 53 & 100,0 \\
\hline Status Hubungan & & \\
Ayah & 14 & 26,4 \\
Ibu & 28 & 52,8 \\
Lain-lain (Kakak, Nenek, tante) & 11 & 20,8 \\
Total & 53 & 100,0 \\
\hline Pendidikan Keluarga & & 9,4 \\
SD & 5 & 9,4 \\
SMP & 5 & 58,5 \\
SMA & 31 & 22,6 \\
Perguruan Tinggi & 12 & 100,0 \\
Total & 53 &
\end{tabular}

Berdasarkan Table 1. Tentang karakteristik keluarga yang memiliki anak usia 3-6 tahun berdasarkan umur menunjukkan bahwa dari 53 responden sebagian besar berumur 30-39 tahun yaitu sebayak $22(41,5 \%)$ dan sebagian kecil berumur 40 tahun yaitu 6 (11,3\%). Keluarga yang memiliki status hubungan sebagai ibu lebih banyak yaitu 28 (52,8\%) dan yang berpendidikan SMA jauh lebih banyak dibanding yang lainnya yaitu sebesar $31(58,5 \%)$. 
Tabel 2. Karakteristik Responden Berdasarkan Jenis kelamin, dan Lama Rawat pada Anak Prasekolah Di Ruang Baji Minasa RSUD Labuang Baji Makassar

\begin{tabular}{ccc}
\hline \multirow{2}{*}{ Jenis Kelamin } & $\mathrm{n}$ & Jumlah \\
\cline { 2 - 3 } & 35 & 66,0 \\
Laki-laki & 18 & 34,0 \\
Perempuan & 53 & 100,0 \\
Total & & \\
Lama Rawat & 34 & 64,2 \\
1-3 Hari & 19 & 35,8 \\
4-6 Hari & 53 & 100,0 \\
Total & & \\
\hline
\end{tabular}

Berdasarkan Tabel 2. Tentang karakteristik jenis kelamin menunjukkan anak laki-laki lebih banyak dibanding anak perempuan yaitu $35(66,0 \%)$, sedangakan anak dengan lama rawat 1-3 hari lebih banyak dibanding anak dengan lama rawat 4-6 hari yaitu $34(64,2 \%)$.

Analisa Univariat

Analisa univariat merupakan analisa data yang meliputi variabel penelitian yaitu family centered care, Penyampaian informasi, partisipasi keluarga, kerjasama keluarga dan dampak hospitalisasi.

Tabel 3. Distribusi Responden Berdasarkan Family Centered Care, Penyampaian Informasi, Partisipasi Keluarga Kerjasama Keluarga dan Dampak Hospitalisasi pada Anak Prasekolah Di Ruang Baji Minasa RSUD Labuang Baji Makassar

\begin{tabular}{ccc}
\hline Family Centered Care & $\mathrm{n}$ & Jumlah \\
\cline { 2 - 3 } & 47 & 88,7 \\
Baik & 6 & 11,3 \\
Kurang Baik & 53 & 100,0 \\
Total & & \\
Baik & 44 & 83,0 \\
Kurang & 9 & 17,0 \\
Total & 53 & 100,0 \\
\hline Penyampaian Informasi & \\
Aktif & & 96,2 \\
Kurang Aktif & 51 & 3,8 \\
Total & 2 & 100,0 \\
\hline Partisipasi Keluarga & 53 & 92,5 \\
Aktif & & 7,5 \\
Kurang Aktif & 49 & 100,0 \\
Total & 4 & 81,1 \\
Kerjasama Keluarga & 53 & 18,9 \\
Stres Ringan & & 100,0 \\
Tidak Sedang & 43 &
\end{tabular}


Berdasarkan Tabel 3. Menunjukkan bahwa distribusi responden dengan family sentered care didapatkan yang baik lebih banyak yaitu 47 (88,7\%) dibanding yang kurang baik, Penyampaian informasi yang baik juga lebih banyak yaitu $44(81,1 \%)$ dibanding yang kurang, Partisipasi keluarga yang aktif lebih banyak 51 (96,2\%) dibanding yang kurang aktif, Kerjasama keluarga yang aktif lebih banyak yaitu 49(92,5\%) dibanding yang tidak aktif dan Dampak Hospitalisasi juga lebih banyak yang stres ringan yaitu $43(81,1 \%)$ dibanding yang stres sedang.

\section{Analisa Bivariat}

Analisa bivariat merupakan analisa data dengan menggunakan uji statistik Ci Square yang melihat hubungan variabel penelitian yaitu hubungan Family cetered care (penyampaian informasi kepada keluarga dengan dampak hospitalisasi pada anak prasekolah, hubungan partisipasi orang tua dalam pengambilan keputusan dengan dampak hospitalisasi pada anak prasekolah dan hubungan kerjasama antara orang tua dan perawat dengan dampak hospitalisasi pada anak prasekolah)

Tabel 4. Hubungan Family Centered care (Penyampaian Informasi kepada Keluarga) dengan Dampak Hospitalisasi pada Anak Prasekolah Di Ruang Baji Minasa RSUD Labuang Baji

\section{Makassar}

\begin{tabular}{|c|c|c|c|c|c|c|c|}
\hline \multirow{3}{*}{$\begin{array}{c}\text { Family Centered care } \\
\text { (Penyampaian informasi kepada } \\
\text { keluarga) }\end{array}$} & \multicolumn{4}{|c|}{ Dampak Hospitalisasi } & & & \multirow{3}{*}{$\begin{array}{c}\rho= \\
\text { Value }\end{array}$} \\
\hline & \multicolumn{2}{|c|}{$\begin{array}{c}\text { Stres } \\
\text { Ringan }\end{array}$} & \multicolumn{2}{|c|}{$\begin{array}{l}\text { Stres } \\
\text { Sedang }\end{array}$} & \multicolumn{2}{|c|}{ Total } & \\
\hline & n & $\%$ & $\mathbf{n}$ & $\%$ & $\mathbf{n}$ & $\%$ & \\
\hline Baik & 39 & 88,6 & 5 & 11,4 & 44 & 100,0 & \\
\hline Kurang Baik & 4 & 44,4 & 5 & 55,6 & 9 & 100,0 & 0,000 \\
\hline Total & 43 & 81,1 & 10 & 18,9 & 53 & 100,0 & \\
\hline
\end{tabular}

Berdasarkan table 4. menunjukkan bahwa penyampaian informasi kepada Keluarga cecara baik dengan dampak hospitalisasi stres ringan lebih banyak $39(88,6 \%)$ dibanding yang stres sedang $5(11,4 \%)$ anak prasekolah, sedngkan Penyampaian Informasi kepada keluarga secara kurang baik dengan dampak hospitalisasi stres ringan sebanyak $4(44,4 \%)$ lebih sedikit dibanding yang stres sedang yaitu $5(55,6 \%)$. Hasil uji statistik chi square di dapatkan bahwa $\rho$ value $=0,00$ lebih kecil dari $\alpha=0,005$ yang artinya ada hubungan signifikan antara penyampaian informasi kepada keluarga dengan dampak hospitalisasi pada anak prasekolah di ruang Baji Minasa RSUD Labuang Baji Makassar.

Tabel 5. Hubungan Family Centered care (Partisipasi Keluarga) dengan Dampak Hospitalisasi pada Anak Prasekolah Di Ruang Baji Minasa RSUD Labuang Baji

Makassar

\begin{tabular}{|c|c|c|c|c|c|c|c|}
\hline \multirow{3}{*}{$\begin{array}{l}\text { Family Centered care } \\
\text { (Partisipasi Keluarga) }\end{array}$} & \multicolumn{4}{|c|}{ Dampak Hospitalisasi } & \multirow{2}{*}{\multicolumn{2}{|c|}{ Total }} & \multirow{3}{*}{$\begin{array}{c}\rho= \\
\text { Value }\end{array}$} \\
\hline & \multicolumn{2}{|c|}{ Stres Ringan } & \multicolumn{2}{|c|}{ Stres Sedang } & & & \\
\hline & $\mathbf{n}$ & $\%$ & $\mathbf{n}$ & $\%$ & $\mathbf{n}$ & $\%$ & \\
\hline Aktif & 43 & 84,3 & 8 & 15,7 & 51 & 100,0 & \\
\hline Kurang Aktif & 0 & 0,0 & 2 & 100,0 & 2 & 100,0 & 0,003 \\
\hline Total & 43 & 81,1 & 10 & 18,9 & 53 & 100,0 & \\
\hline
\end{tabular}

Berdasarkan tabel 5. Menunjukkan bahwa partisipasi Keluarga cecara aktif dengan dampak hospitalisasi stres ringan lebih banyak 43 (84,3\%) dibanding yang stres sedang 8(15,7\%) anak prasekolah, sedngkan partisipasi keluarga yang kurang aktif dengan dampak hospitalisasi stres 
ringan tidak ada dibanding yang stres sedang yaitu 2(100\%). Hasil uji statistik chi square di dapatkan bahwa $\rho$ value $=0,003$ lebih kecil dari $\alpha=0,005$ yang artinya ada hubungan signifikan antara Partisipasi keluarga dengan dampak hospitalisasi pada anak prasekolah di ruang Baji Minasa RSUD Labuang Baji Makassar.

Tabel 6. Hubungan Family Centered care (Kerjasama Keluarga) dengan Dampak Hospitalisasi pada Anak Prasekolah Di Ruang Baji Minasa RSUD Labuang Baji Makassar

\begin{tabular}{|c|c|c|c|c|c|c|c|}
\hline \multirow{3}{*}{$\begin{array}{l}\text { Family Centered care } \\
\text { (Kerja Sama Keluarga) }\end{array}$} & \multicolumn{4}{|c|}{ Dampak Hospitalisasi } & \multirow{2}{*}{\multicolumn{2}{|c|}{ Total }} & \multirow{3}{*}{$\begin{array}{c}\rho= \\
\text { Value }\end{array}$} \\
\hline & \multicolumn{2}{|c|}{ Stres Ringan } & \multicolumn{2}{|c|}{ Stres Sedang } & & & \\
\hline & $\mathbf{n}$ & $\%$ & $\mathbf{n}$ & $\%$ & $\mathbf{n}$ & $\%$ & \\
\hline Aktif & 42 & 85,7 & 7 & 14,3 & 49 & 100,0 & \\
\hline Kurang Aktif & 1 & 25 & 3 & 75 & 4 & 100,0 & 0,001 \\
\hline Total & 43 & 81,1 & 10 & 18,9 & 53 & 100,0 & \\
\hline
\end{tabular}

Berdasarkan tabel 6. Menunjukkan bahwa Kerja Sama Keluarga cecara aktif dengan dampak hospitalisasi stres ringan lebih banyak 42 (85,7\%) dibanding yang stres sedang $7(14,3 \%)$ anak prasekolah, sedngkan Kerja Sama Keluarga yang kurang aktif dengan dampak hospitalisasi stres ringan tidak ada dibanding yang stres sedang yaitu 2(100\%). Hasil uji statistik chi square di dapatkan bahwa $\rho$ value $=0,001$ lebih kecil dari $\alpha=0,005$ yang artinya ada hubungan signifikan antara Kerjasama keluarga dengan dampak hospitalisasi pada anak prasekolah di ruang Baji Minasa RSUD Labuang Baji Makassar.

\section{PEMBAHASAN}

Hubungan Family Centered care (Penyampaian Informasi kepada Keluarga) dengan Dampak Hospitalisasi pada Anak Prasekolah Di Ruang Baji Minasa RSUD Labuang Baji Makassar

Hasil uji statistik menunjukkan $\rho$ value $=0,000<\alpha 0,005$ yang artinya ada hubungan signifikan penyampaian informasi dengan dampak hospitalisasi pada anak prasekolah di Baji Minasa RSUD Labuang Baji Makassar. Hal ini dikarenakan sebagian besar atau 88,6\% keluarga mengatakan hanya mengalami stress ringan setelah mendapakan penyampaian informasi dengan baik dari petugas kesehatan diruang perawatan, dengan demikian dampak hospitalisasi cenderung dapat diminimalisir oleh adanya penyampaian informasi secra baik dan benar. Menurut Lory (2011) bahwa memberikan informasi kesehatan pada keluarga tentang kondisi kesehatan anak dapat meningkatkan peran keluarga dan mengontrol perawatan anak selama hospitalisasi. Hubungan yang baik dan saling percaya antara perawat dengan keluarga dapat menimbulkan rasa nyaman dan dapat meminimalkan dampak hospitalisasi. (Lory, 2011).

Informasi dapat diberikan melalui komunikasi teraupetik. Komunikasi teraupetik yang dimaksudkan antara perawat dan keluarga tidak hanya sebatas sebagai alat pembuat keputusan atau pertukaran informasi untuk melengkapi proses keperawatan tetapi kualitas, keefektifan, efisiensi komunikasi untuk menciptakan ekspektasi yang positif bagi perawat dan keluarga tua. Selain itu, kewajiban perawat dalam melakukan intervensi keperawatan mandiri atau yang didelegasikan harus menjalin dan mempertahankan hubungan saling percaya yang baik (rapport) dengan pasien. Perawat harus memastikan bahwa keluarga dan anak memperoleh informasi mengenai diagnose dan rencana tindakan, memberikan umpan balik terhadap setiap perkembangan kondisi dan menunjukkan rasa kepedulian untuk mencegah rasa ketidakberdayaan dan putus asa yang dirasakan oleh klien. (Fisher dkk, 2011).

Hasil penelitian ini didukung oleh penelitian yang dilakukan oleh Ardianingsih (2009), didapatkan bahwa anak usia prasekolah yang mendapatkan penyampaian informasi baik, $0 \%$ yang mengalami kecemasan tingkat tinggi, sedangkan $100 \%$ mengalami kecemasan sedang. Anak yang 
mendapatkan dukungan informasi kurang 50\% yang mengalami kecemasan tingkat tinggi, 46,1\% mengalami kecemasan tingkat sedang dan 3,9\% mengalami kecemasan tingkat rendah. Anak dan keluarga sangat memerlukan penyampaian informasi, berbagai macam informasi diperlukan keluarga dan perawat selama anak menjalani hospitalisasi. Penyampaian informasi dapat membantu keluarga dan anak dalam membentuk koping selama hospitalisasi, (Ardianingsih, 2009). Penyampaian informasi kepada keluarga di rumah sakit, memungkinkan keluarga lebih mengetahui perkembangan kondisi anak dirumah sakit dan menilai penerapan Family Centered Care yang dilakukan oleh perawat di ruang Baji Minasa RSUD Labuang Baji Makassar.

Semakin baik dan semakin lengkap penyampaian informasi kesehatan yang diberikan maka dampak hospitalisasi anak akan semakin berkurang seiring bertambahnya informasi pada keluarga. Informasi yang jelas sangat penting bagi klien atau keluarga untuk mengatasi dampak hospitalisasi akibat kurangnya informasi. Tingkat dampak hospitalisasi berkurang bila diberikan informasi kesehatan disbanding dengan tidak sama sekali, (Herliana, 2010).

Hal ini juga ditunjang oleh tingkat pendidikan keluarga yang memiliki anak usia 3-6 tahun yang sedang menjalani perawatan di ruang Baji Minasa RSUD Labuang Baji Makassar yaitu $50 \%$ ibu berpendidikan SMA sehingga keluarga mudah menyerap informasi mengenai perawatan anak di rumah sakit dan peran mereka dalam merawat anak. Informasi ini membantu keluarga untuk bersikap dan bertindak melibatkan diri dalam merawat anak sehingga mengurangi dampak hospitalisasi yang dialami oleh anak mereka. Hal ini sejalan dengan pendapat, (Suriani, 2011).

Namun hasil lain tentang penerapan Family Centered Care dalam penyampaian informasi didapatkan juga ada sebanyak 11,4\% anak prasekolah yang tetap mengalami stress sedang dari dampak hospitalisasi walau penyampaian informasinya baik, ini dapat dikarenakan umur anak prasekolah yang sedang menjalani perawatan di RSUD Labuang Baji Makassar yang sebanyak 67,9\% berumur 3-4 tahun. Berdasarkan perkembangan kognitif menurut Piaget yang menyebutkan pada anak usia prasekolah (3-6 tahun) berada pada fase peralihan antara prakonseptual (3 sampai 4 tahun) dan intuitif (5 sampai 6 tahun) (Muscari, 2005). Semakin muda usia anak, maka akan semakin sulit bagi anak untuk menyesuaikan diri dengan lingkungan. Hal ini berhubungan dengan system imun anak akan terus berkembang seiring dengan bertambahnya usia anak, (Sacharin, 1996)

Hubungan Family Centered care (Partisipasi Keluarga) dengan Dampak Hospitalisasi pada Anak Prasekolah Di Ruang Baji Minasa RSUD Labuang Baji Makassar

Hasil uji statistik menunjukkan $\rho$ value $=0,003<\alpha 0,005$ yang artinya ada hubungan signifikan partisipasi keluarga dengan dampak hospitalisasi pada anak prasekolah di Baji Minasa RSUD Labuang Baji Makassar. Hal ini dikarenakan sebagian besar atau 43 (84,3\%) keluarga berpartisipasi aktif dalam membantu proses pelayanan keperawatan. Cara untuk meminimalkan dampak negatif dari hospitalisasi adalah perawat melibatkan keluarga dalam perawatan dan mendorong peran serta dalam perawatan.

Penelitian ini didukung oleh peneliti sebelumya yaitu keluarga bisa berpartisipasi, mendukung dan melindungi pasien untuk mampu beradaptasi dengan kondisi pasien yang dirawat. Peran serta keluarga perlu ditingkatkan pada saat merawat anak di rumah sakit. Peran keluarga tidak bisa maksimal jika tidak di dukung oleh perawat (Davidson, 2009).

Peran perawat dalam meminimalkan dampak hospitalisasi sangatlah penting. Salah satu tindakan yang penting yang dapat dilakukan untuk mengurangi dampak hospitalisasi adalah melibatkan keluarga untuk terlibat aktif dalam perawatan anak, salah satunya dengan membolehkan keluarga untuk tinggal bersama anak selama 24 jam, hal ini merupakan salah satu bagian dari pelayanan Family Centered Care, (Yupi, 2010). Hal ini juga ditunjang dengan tingkat usia keluarga yang memiliki anak berumur 3-6 tahun sedang menjalani perawatan di ruang Baji Minasa RSUD Labuang Baji Makassar yaitu hampir 50\% adalah berusia diatas 30 tahun sehingga dengan usia tersebut usia produktif dimana keluarga telah mengalami pengalaman hidup yang 
banyak sehingga keluarga mampu melaksanakan pemecahan masalah dan pengambilan keputusan yang lebih baik daripada orang-orang yang mempunyai usia dibawahnya.

Hubungan Family Centered care (Kerjasama Keluarga) dengan Dampak Hospitalisasi pada Anak Prasekolah Di Ruang Baji Minasa RSUD Labuang Baji Makassar

Hasil uji statistik menunjukkan $\rho$ value $=0,001<\alpha$ 0,005 yang artinya ada hubungan signifikan Kerjasama keluarga dengan dampak hospitalisasi pada anak prasekolah di Baji Minasa RSUD Labuang Baji Makassar. Hal ini cenderung diakibatkan oleh sebagian besar keluarga mampu bekerjasama dengan perawat secra aktif sehingga dampak hospitalisasi berupa stres sedang lebih sedikit dibanding yang stres ringan saja yaitu $42(85,7 \%)$.

Hasil penelitian sebelumnya menjelaskan bahwa terdapat hubungan antara peran serta keluarga dan dampak hospitalisasi pada anak prasekolah. Keterlibatan keluarga dalam perawatan membuat anak mampu mengembangkan diri secara pribadi dan memberikan sikap positif keluarga sehingga perawatan pada anak lebih optimal. (Biyanti, 2012). Pelayanan Family Centered Care memberdayakan kemampuan keluarga baik dalam aspek pengetahuan keterampilan, maupun sikap dalam dalam melaksanakan perawatan anaknya dirumah sakit melalui interaksi yang teraupetik dengan keluarga, (Yupi, 2010).

Perawat dalam melakukan perawatan anak harus mempertimbangkan untuk menghadirkan keluarga pada saat dilakukan prosedur yang menimbulkan nyeri, (Hidayat, 2005). Setiap asuhan pada anak yang dirawat dirumah sakit memerlukan keterlibatan keluarga. Untuk mencapai tujuan dari pencegahan dan pengobatan pada anak yang dirawat di rumah sakit, sangat diperlukan kerja sama antara tim kesehatan dan keluarga, serta asuhan pada anak yang paling baik adalah dilakukan oleh keluarga. Terbukti dalam beberapa penelitian bahwa anak akan merasa aman apabila berada di samping keluarganya, terlebih lagi pada saat menghadapi situasi menakutkan seperti dilakukan prosedur invasive, (Yupi, 2010). Lingkungan keluarga sangat menentukan kehidupan anak, sehingga keperawatan anak harus mengenal keluarga sebagai tempat tinggal atau konstanta tetap dalam kehidupan anak. Keluarga adalah unsure yang paling dekat dengan anak mengingat anak bagian dari keluarga, (Hidayat, 2005).

Menurut Supartini (2010) roomin in atau pendampingan keluarga selama menjalani perawatan di rumah sakit akan membantu meminimalkan stress yang dialami oleh anak maupun keluarga karena perpisahan. Hal ini sesuai dengan hasil peneliian bahwa adanya $75 \%$ anak prasekolah yang mengalami stress dari dampak hospitalisasi karena kerjasama keluarga yang kurang aktif. Selain itu, keberadaan keluarga selama perawatan anak di rumah sakit bertujuan untuk memberikan kesempatan pada keluarga untuk terlibat aktif dalam perawatan anak di rumah sakit.

Keluarga memiliki peran yang sangat penting dalam meningkatkan kesehatan anaknya, menjadi perantara utama dalam perawatan langsung kepada anak, dan menyediakan akses untuk pelayanan kesehatan. Sikap dan perilaku keluarga dapat mempengaruhi kesehatan fisik dan psikologi anak. Sikap keluarga selama sakit, khususnya selam hospitalisasi dapat mempengaruhi ketaatan anak dalam perawatan dan dampak penyakit, (Commodary, 2010)

Peran keluarga yang dipaparkan oleh Chen (2005) menjelaskan bahwa bentuk peran serta keluarga selama anak dirawat di rumah sakit adalah dengan menjalin kolaborasi antara keluarga dengan profesi kesehatan dan kehadiran keluarga yang dapat memberikan rasa nyaman pada anak. Bentuk kolaborasi keluarga dan profesi kesehatan di wujudkan dengan adanya keterlibatan keluarga dalam perawatan, memberikan support emosional kepada anak, ikut terlibat pada tindakan sederhana, menjelaskan kepada anak tentang kondisi anak dan memenuhi kebutuhan anak selama dirawat, (Chen, 2005). Hal ini sejalan dengan penelitian sebelumnya bahwa bahwa ada hubungan antara Family Centered Care dengan dampak hospitalisasi. Efek hospitalisasi pada anak di pengaruhi perkembangan usia, pengalaman dirawat di rumah sakit, dukungan dari lingkungan sosial dan mekanisme koping. (Fiane, 2012.) 


\section{SIMPULAN}

Berdasarkan hasil analisis dan pembahasan penelitian tentang hubungan Family Centered Care dengan Dampak Hospitalisasi pada Anak Prasekolah Di RSUD Labuang Baji Makassar maka dapat ditarik kesimpulan bahwa terdapat hubungan yang signifikan antara penyampaian informasi dengan dampak hospitalisasi pada anak dengan hasil uji statistic diperoleh $p$ value $=0,000<\alpha$ 0,005, ada hubungan yang signifikan antara partisipasi orang tua dengan dampak hospitalisasi pada anak prasekolah dengan hasil uji statistic diperoleh $\mathrm{p}$ value $=0,003<\alpha 0,005$, dan ada hubungan yang signifikan antara kerjasama orang tua dengan dampak hospitalisasi pada anak prasekolah dengan hasil uji statistic diperoleh $p$ value $=0,001<\alpha 0,005$.

\section{SARAN}

Saran diberikan kepada pihak-pihak yang mendapatkan manfaat penelitian agar melakukan tindakan berdasarkan hasil dan bahasan penelitian, ditulis secara singkat dan jelas dengan huruf Book Antiqua, font 11, spasi 1 dan ukuran kertas yang digunakan adalah a4, dengan margin top 1", bottom 1", left 0,75" and right 0,75" (dalam satuan inchi), atau margin top 2,54 cm, bottom 2,54 cm, left 1,90 cm dan right $1,90 \mathrm{~cm}$ (dalam satuan sentimeter).

Berdasarkan hasil penelitian, pembahasan dan kesimpulan di atas, maka peneliti menyarankan kepada Perawat Agar tetap mempertahankan pendekatan Family Centered Care yang telah dilakukan serta lebih meningkatkan dalam hal partisipasi keluarga dalam pengambilan keputusan. selain itu, perlunya menambah wawasan dan mengevaluasi aplikasi pendekatan Family Centered Care yang belum dan telah dilakukan melalui hasil-hasil penelitian yang terkait meningkatkan kualitas pelayanan yang diberikan dalam bentuk asuhan keperawatan. Bagi Rumah Sakit diharapkan untuk menyelenggarakan pelatihan untuk meningkatkan pengetahuan sikap, dan keterampilan perawat dalam melaksanakan Family Centered Care serta memotivasi perawat untuk memperhatikan peran perawat dalam memberikan asuhan keperawatan dengan memperhatikan peran perawat. Bagi peneliti selanjutnya, agar lebih mengembangkan penelitian ini menggunakan metode kualitatif dan eksperimen untuk mengetahui faktor lain yang mempengaruhi terjadinya efek hospitalisasi dan penanganan efek hospitalisasi yang dapat dilakukan untuk memberikan pengaruh positif bagi perkembangan anak yang mengalami hospitalisasi.

\section{DAFTAR PUSTAKA}

Ardianingsih. (2009). Hubungan Dukungan Informasional Dengan tingkat Kecemasan Anak Usia Prasekolah di RSUD Banyumas. Jurnal Keperawatan Soedirman; 1 No 1, 1-.

CDC. (2015). Centers for Disease Control and Prevention. -: Summary of Weekly Flu View, 24.

Chen, W. L. (2005). Nurse's and parent's attitudes toward pain management and parental participation in postoperative care of children. The Queensland: Thesis, Centre for Reseach The Queensland University of Technology.

Commodary, E. (2010). Children Staying In Hospital: A Research On Psychological Stress Of Caregivers. Italian Journal of Pediatrics, 36:40.

Davidson, J. E. (2009). Family Centered Care : Meeting the Needs of Patient Families ang Helping Families Adapt to Critical Illnes. Critical Nurse, 28-34.

Fiane. (2012.). Hubungan Family Centered Care Dengan Hospitalisasi Pada Anak Di Ruang Dahlia Rumah Sakit Panti Wilasa Citarum Semarang . Semarang: Skripsi. Salatiga : Universitas Kristen Satya Wacana.

Herliana. (2010). Hubungan pendidikan kesehatan dengan tingkat kecemasan pasien pre operasi seksio caesarea di ruang bersalin RS. Zahirah . Jakarta Selatan: -. 
Hidayat, A. A. (2005). Pengantar Ilmu Keperawatan Anak, Ed I. Jakarta: Salemba Medika.

Hudriyah, E. S. (2013). Hubungan Dukungan Keluarga dan Lingkungan Rumah Sakit Dengan

Reaksi Hospitalisasi Pada Anak Usia Prasekolah di RSUP Dr. Wahidin Sudirohusodo

Makassar. http://library.stikesnh.ac.id/files/disk1/8/e-library-stikes-na, 32-33.

Lory. (2011). Family Centered Care; Emla Cream and Application of Heat to Facilitate Peripheral Venous Cannulation In Children. -: - .

Potter , \& Perry. (2005). Fundamental Keperawatan. Jakarta: EGC.

Sacharin, R. M. (1996). Prinsip Keperawatan Pediatrik, Edisi 2. Jakarta: EGC.

Suriani. (2011). HUbungan Dukungan Keluarga Dengan Tingkat Kecemasan Hospitalisasi Pada Anak Usia Sekolah di Ruang Perawatan Anak Paviliun DII \& Paviliun V RS TNI AL. Dr. Ramelan Kota Surabaya. Jurnal Infokes Stikes Insan Unggul Surabaya, 11-20.

Wong, D. L. (2009). Buku Ajar Keperawatan Pediatrik. Volume 1 Edisi 6. Jakarta: EGC.

Yupi, S. (2010). Buku Ajar Konsep Dasar Keperawatan Anak. Jakarta : EGC. Jakarta: EGC. 